\title{
Aleitamento materno: fatores Que levam ao desmame precoce
}

\author{
Brastfeeding: factors that cause early weaning \\ Lactáncia: factores que llevan al destete precoz
}

\author{
Olívia Dias de Araújo', Adélia Leana da Cunha", Lidiana Rocha Lustosa", \\ Inez Sampaio Nery', Rita de Cássia Magalhães Mendonça', Sônia Maria de Araújo Campelo' \\ 'Unversidade Federal do Piauí. Teresina, PI \\ "Universidade Estadual do Piauí. Teresina, PI
}

Submissão: 13/03/2008

Aprovação: 31/07/2008

\section{RESUMO}

Este estudo teve como objetivos identificar os motivos Que levaram as mulheres ao desmame precoce e analisar o conhecimento das mães sobre o aleitamento materno. Trata-se de uma pes Quisa de abordagem Qualitativa, realizada em Teresina-Pi, com onze mães, na faixa etária de 18 a 43 anos, Que desmamaram precocemente. Os relatos dos sujeitos, a partir da entrevista semi-estruturada, possibilitaram o surgimento de duas categorias: Compreensão sobre amamentação; e Fatores que levaram ao desmame precoce. As análises revelaram Que os fatores Que motivaram ao desmame precoce foram: enfermidades da mãe Que impediram o aleitamento; medicamentos utilizados por elas; e substituição do leite materno por outro alimento. Evidenciou-se também que o conhecimento sobre aleitamento materno está pautado em discurso biomédico de saúde-doença.

Descritores: Aleitamento materno; Desmame precoce; Enfermagem.

\begin{abstract}
This study aimed to identify the reasons which made mothers wean their children early and analyze their knowledge on breastfeeding. It is about a research of eualitative approach and was developed in Teresina-Pi, with I I (eleven) mothers, aged between 18 and 43 years old, who weaned early. The reports of the subjects, from the semi-structured interview, enabled the emergence of two categories: Understanding on breastfeeding and Factors that led to early weaning. The analyses showed that the factors which led to early weaning were: mother's illness that damaged the breastfeeding; medicines used by them and the feeding of the infants with another kind of food. It also put in evidence that the knowledge on breastfeeding is based on a strongly biomedical health-disease speech.
\end{abstract}

Descriptors: Breastfeeding; Early weaning; Nursing.

\section{RESUMEN}

Este estudio tuvo como objetivos identificar las razones que llevaron las mujeres a destetar sus hijos precozmente y analizar el conocimiento de las madres a cerca de la lactancia. Es una pesquisa de abordaje cualitativo y fue desarrollada en Teresina Pi, con 11 madres, de 18 hasta 43 años, Que destetarón precozmente. Los resultados de los sujetos, a partir de la entrevista semi-estructurada posibilitaron el aparecimiento de dos categorías: Comprensión sobre lactancia y Factores Que llevaron al destete precoz. Las análisis revelaron que los factores Que motivaron el destete precoz fueron: enfermedad de la madre Que impidió la lactancia; medicamentos utilizados por ellas y el ofrecimiento de otro tipo de alimento al lactante. También mostró Que ele conocimiento sobre lactancia está basado en discurso fuertemente biomédico de salud-enfermedad.

Descriptores: Lactáncia; Destete precoz; Enfermería. 


\section{INTRODUÇÃO}

A preocupação com os efeitos deletérios do desmame precoce representa uma unidade nas agendas de saúde coletiva do Brasil de hoje. Os modelos explicativos para a relação amamentação desmame multiplicam-se e sinalizam para o embate entre saúde e doença, evidenciando os condicionantes sociais, econômicos, políticos e culturais Que transformaram a amamentação em um ato regulável pela sociedade ${ }^{(1)}$.

A amamentação não é totalmente instintiva no ser humano, muitas vezes deve ser aprendida para ser prolongada com êxito, considerandose Que a maioria das nutrizes precisa de esforço e apoio constantes. Nesse sentido, as mulheres, ao se depararem pela primeira vez com o aleitamento materno, requerem Que lhes sejam apresentados modelos ou guias práticos de como devem conduzir-se nesse processo, Que na maioria das vezes tem como primeira referência o meio familiar, as amizades e vizinhança nos Quais estão inseridas ${ }^{(2)}$.

Nesse contexto, observa-se a necessidade de rever o posicionamento do profissional diante da mulher Que deseja amamentar. E torna-se preciso reconhecer Que, por ser uma prática complexa, não se deve reduzir apenas aos aspectos biológicos, mas incluir a valorização dos fatores psicológicos e socioculturais. Além disso, é fundamental que o profissional permita que a mulher coloque suas vivências e experiências anteriores, uma vez Que a decisão de amamentar está diretamente relacionada ao Que ela já viveu ${ }^{(3)}$.

Partindo desse enfoque, acrescenta-se Que o aleitamento materno depende de fatores Que podem influir positiva ou negativamente no seu sucesso. Alguns desses fatores estão diretamente relacionados à mãe, como as características de sua personalidade e sua atitude frente à situação de amamentar, ao passo Que outros se referem à criança e ao ambiente, como por exemplo, as suas condições de nascimento e o período pós-parto havendo, também, fatores circunstanciais, como o trabalho materno e as condições habituais de vida $^{(4)}$.

Outro fato importante é que a idade materna mais jovem está relacionada à menor duração do aleitamento, talvez motivada por algumas dificuldades, tais como: um nível educacional mais baixo, poder aQuisitivo menor e, muitas vezes, o fato de serem solteiras. As adolescentes muitas vezes aliam sua própria insegurança e falta de confiança em si mesmas para prover a alimentação para o seu bebê à falta de apoio das próprias mães ou familiares mais próximos, ao egocentrismo próprio dessa idade e aos problemas com a autoimagem, alcançando freqüentemente, um menor índice de aleitamento $^{(5)}$.

E no Que se refere ao grau de instrução materna, estudos têm demonstrado Que esse fator afeta a motivação para amamentar. Em muitos países desenvolvidos, mães com maior grau de instrução tendem a amamentar por mais tempo, em decorrência principalmente da possibilidade de um maior acesso a informações sobre as vantagens do aleitamento materno. Já em países em desenvolvimento, as mães de classes menos favorecidas e instruídas, freqüentemente, não casadas, começam o pré-natal mais tarde e, conseQüentemente, se preocupam em decidir sobre a forma de alimentação do bebê também mais tarde ${ }^{(6)}$

Nesse sentido, o desmame é definido como a introdução de QualQuer tipo de alimento na dieta de uma criança Que, até então, se encontrava em regime de aleitamento materno exclusivo. Dessa forma, denomina-se "período de desmame" aquele compreendido entre a introdução desse novo aleitamento até a supressão completa de aleitamento materno ${ }^{(7)}$.

O desmame precoce sofre influência de variáveis Que afetam o desmame precoce ou a extensão da amamentação podendo ser divididas em cinco categorias: a) variáveis demográficas: tipo de parto, idade materna, presença paterna na estrutura familiar, números de filhos, experiência com amamentação; b) variáveis socioeconômicas: renda familiar, escolaridade materna e paterna, tipo de trabalho do chefe de família; c) variáveis associadas à assistência pré-natal: orientação sobre amamentação desejo de amamentar; d) variáveis relacionadas à assistência pós-natal imediata: alojamento conjunto, auxílio de profissionais de saúde, dificuldades iniciais; e) variáveis relacionadas à assistência pós-natal tardia (após a alta hospitalar): estresse e ansiedade materna, uso de medicamentos pela mãe e pelo bebê, introdução precoce de alimentos ${ }^{(8)}$.

Nessa perspectiva, ao longo do tempo criaram-se alternativas para responder à demanda das mulheres Que, por opção ou imposição, trilharam o caminho do desmame precoce, desde a secular ama-deleite até a emblemática vanguarda científica construída pelo marketing dos fabricantes de leites modificados, em Que a alimentação do lactente tem servido a propósitos Que não se circunscrevem exclusivamente às Questões ligadas à saúde, mas a interesses de auferir lucros de toda espécie ${ }^{(1)}$.

Em virtude das observações realizadas e da inserção direta na problemática suscitada, o desmame precoce, constatou-se um elevado número de casos, fato esse Que motivou as autoras a realizarem este estudo, partindo das seguintes Questões norteadoras: Qual o conhecimento Que as mães têm sobre aleitamento materno? Quais os fatores Que levaram as mães ao desmame precoce?

Partindo da reflexão sobre a problemática evidenciada e com intuito de responder a esses Questionamentos foram elaborados os seguintes objetivos: identificar os motivos Que levaram as mulheres a desmamarem seus filhos precocemente; e analisar os motivos e o conhecimento das mães sobre o aleitamento materno.

\section{METODOLOGIA}

O estudo constituiu-se em uma pesquisa Qualitativa. O universo empírico considerado foi de mães Que desmamaram seus filhos precocemente (antes dos seis meses de idade), residentes no bairro Mafrense, zona norte do município de Teresina-PI, onde funcionam duas Equipes de Saúde da Família sob a égide da Fundação Municipal de Saúde em Teresina-PI.

O recorte empírico do estudo foi constituído por onze mães, selecionadas por meio da equipe da Estratégia Saúde da Família, utilizando-se como critérios de inclusão mães Que desmamaram precocemente.

O grupo de mães encontrava-se na faixa etária de 18 a 43 anos, cuja situação conjugal caracteriza-se por sete dessas serem casadas, três apresentarem união estável e uma estar solteira. As mulheres, sujeitos deste estudo, em sua maioria possuíam dois filhos ou mais. E Quanto ao grau de escolaridade, verificou-se que cinco possuíam o ensino fundamental, Quatro encontravam com o ensino médio incompleto, e duas com o ensino médio completo. Já em relação à ocupação, sete trabalhavam no lar e Quatro fora do lar, com uma renda familiar que expressa um baixo poder aeuisitivo do grupo, 
considerando-se Que três gozam de uma renda entre 1 a 2 salários, ao passo Que oito mulheres recebem até $0 \mathrm{I}$ salário mínimo.

Em conformidade com a Resolução 196/96, do Conselho Nacional de Saúde, obteve-se a aquiescência das mulheres, para Que as mesmas fizessem parte do estudo. A estas foram informados os objetivos da pesQuisa e solicitada a permissão para uso de suas informações, garantindo-lhes o anonimato e o direito de afastar-se da pesquisa se assim julgassem necessários em QualQuer fase de sua etapa. O estudo foi também previamente aprovado pelo Comitê de Ética e Pesquisa da Universidade Estadual do Piauí, conforme as normas regulamentadoras de pesquisa envolvendo seres humanos.

A coleta de dados realizada pelas autoras ocorreu no período de maio a junho de 2007, cuja técnica empregada foi a entrevista contendo Questões abertas e fechadas. As entrevistas semi-estruturadas foram gravadas em fita $\mathrm{K} 7$ e duraram em torno de uma hora, constituindose numa relação dialógica entre os interlocutores, pois, a entrevista foi entendida neste estudo como uma prática discursiva, uma ação situada e contextualizada, por meio da Qual se produzem sentidos e se constroem versões da realidade.

Nas entrevistas foram abordados os seguintes conteúdos: dados de identificação, conhecimento sobre amamentação, importância do aleitamento materno, dificuldades para realizar o aleitamento materno e fatores Que levaram ao desmame precoce.

O corpus deste estudo foi composto pelos dados das entrevistas, os Quais foram analisados por meio do método de análise de conteúdo(9), Que deu origem a um Plano de Análise e a partir do qual se processou a pré-análise, ordenamento do material e classificação, Que possibilitou agrupar de forma ordenada por similaridade semântica os discursos dos sujeitos em categorias Que foram interpretadas. As discussões dos conteúdos levantados estão fundamentadas nas concepções de aleitamento materno, desmame precoce e enfermagem.

\section{RESULTADOS}

As falas das mulheres foram agrupadas em significados comuns, ordenadas por similaridade semântica, evidenciando os fatores que levaram ao desmame precoce, na tentativa de atingir os objetivos a Que se propôs este estudo. As categorias temáticas Que emergiram a partir dos relatos das depoentes foram: compreensão sobre amamentação; e fatores Que levaram ao desmame precoce.

\section{Compreensão sobre Amamentação}

A compreensão das mulheres sobre amamentação influencia de forma direta a atitude das mesmas frente ao ato de amamentar. Através das informações das depoentes, pôde-se verificar um conhecimento intrinsecamente ligado ao discurso biomédico, em Que a amamentação é, sobretudo, para evitar doenças. E em relação à importância do aleitamento materno, notou-se uma valorização, Quanto à proteção imunológica, ao fator nutricional e de afetividade, por parte das mães entrevistadas, como podemos ver nas falas a seguir:

Eu acho que é forte para criança (D8)

Previne doenças e infecções intestinais (DI).

É muito bom principalmente Quando o dente está nascendo, evita diarréia, evita muitas coisas (D9).

É importante porque a gente já tira aQuele trabalho da criança ter um problema de doença, porQue ele tá bem nutrido (D4).

Acho bom pra ele crescer, não ficar doente (D6).

Nas falas das mães sujeitos do estudo constatou-se a relação amamentar versus prevenção de doenças. Essa relação, Que denota um dos benefícios à saúde da criança, tornou-se mais difundida por ter sido amplamente utilizada desde o início dos anos 80 em campanhas oficiais de promoção da amamentação. Nesse sentido, verificou-se Que as mães têm noção dos valores imunológicos do leite materno para a criança, no entanto, ainda é pouco conhecido ou valorizado pelas mães e/ou profissionais os outros benefícios do aleitamento materno(I).

As vantagens do aleitamento materno para o recém-nascido estão vinculadas ao fato de este suprir as necessidades nutricionais da criança por aproximadamente os seis primeiros meses de vida, oferecendo resistência contra infecções e estabelecendo vínculo psicológico mãe e filho. Outros fatores importantes também se relacionam ao ato de amamentar, como: reduzir as malformações da dentição, estimular e exercitar a musculatura Que envolve o processo da fala, promover melhor a dicção e proporcionar tran@üilidade ao recém-nascido ${ }^{(10)}$.

Com relação aos laços afetivos mãe-filho, a mulher Que amamenta não está oferecendo somente leite materno, está vivenciando um momento em Que poderá fazer aflorar sensações prazerosas Que irão influenciar sobremaneira na afetividade da mãe e do filho.

\section{Fatores Que Levaram ao Desmame Precoce}

Enfocando os relatos das mulheres relacionadas ao desmame precoce, a maioria declara Que desmamou seus filhos alegando enfermidades associadas geralmente a medicamentos utilizados, o trabalho fora de casa e ao oferecimento por parte das avós de outro tipo de alimento para o lactante, como se pode observar nas falas a seguir:

Ela não mamou porQue, durante os exames, o doutor notou uma doença em mim e eu tomei muito antibiótico, e segundo os médicos, disseram que afetava o leite e ia passar para ela (DI).

Foi porque com nove dias que eu tive ela, eu voltei para o hospital, porQue tive uma infecção. Quando eu voltei do hospital ela não Quis mais mamar, tava acostumada com a mamadeira (D3).

Não saía leite por nada do meu seio, nem pingava (D4).

O meu trabalho é viajando e a vista dela não Querer também, eu não insistia muito (D9).

Meu peito feriu muito e eu sentia muita dor e eu não agüentava (DI0).

As mães geralmente apresentem noção das vantagens do aleitamento materno e referem doenças maternas ou da criança e o trabalho fora do lar como problemas pouco freQüentes em relação à 
manutenção do aleitamento. Em contrapartida, apontam como relevantes, para a efetivação do desmame precoce, os problemas relacionados à "falta de leite", "leite fraco", problemas mamários e a recusa do bebê em pegar o peito.

Essas razões, apontadas mais freqüentemente, talvez se devam ao fato de a mulher atual ter uma vivência mais ansiosa e tensa e, possivelmente, à falta de um suporte cultural Que havia nas sociedades tradicionais, nas Quais as avós transmitiam às mães informações e um treinamento das mesmas em relação ao aleitamento, incentivandoas para tal ${ }^{(5)}$.

Embora o aleitamento denote grande importância e apresente uma enormidade de vantagens, existem situações Que exigem a necessidade de inibir ou suprimir a produção do leite materno. Uma dessas necessidades está atrelada à presença de certas doenças na mulher, o Que contra-indica a amamentação e reQuer inibição da produção do leite, denominada de "prevenção da lactação" (3).

Contudo, são raras as enfermidades maternas com contra-indicação absoluta à amamentação natural: tuberculose ativa, hanseníase, portadores de vírus HIV, herpes, vírus simples nas mamas, moléstias debilitantes graves, desnutrição materna, necessidade de ingestão de medicamentos nocivos à criança por tempo prolongado e níveis elevados e contaminantes maternos (mercúrio ou fungicida).

Após o parto, Quando a mulher retorna ao seu contexto social, ela sofre interferências na sua forma de pensar e agir com relação ao aleitamento materno. Isso leva a introdução precoce de outros alimentos, Que se inicia geralmente no período Que se segue à alta hospitalar(2).

Com bases nessas concepções, a avó poderá transmitir tabus, crenças e proibições inerentes a um dado contexto histórico-social, atuando dessa forma como elemento desestimulador ou estimulador para a amamentação, considerando-se Que a avó é tomada na família como modelo de referência aos cuidados com o bebê, inclusive ao aleitamento materno ${ }^{(2)}$.

Nesse sentido, a incapacidade de amamentar tornaria pública a impossibilidade, para a mulher de cumprir uma "função natural" e "dever sagrado", o que a inferioriza perante a sociedade. Outro fato Que transcende é o trabalho fora de casa, em Que a inserção da mulher pobre no mercado de trabalho tece um cenário favorável ao desmame.

O crescimento da participação feminina no mercado de trabalho no país foi uma das transformações sociais ocorridas desde os anos 70. As estatísticas mostram a presença cada vez mais intensa da mulher no mercado de trabalho brasileiro e não mostra nenhuma tendência de retrocesso, o Que implica em uma mudança do comportamento da mulher em relação à amamentação(2) .

Em relação aos fatores clínicos Que afetam o aleitamento materno, incluem-se fissuras, ingurgitamento mamário, mastites, hipogalactia, prematuridade, drogas, bem como a infecção puerperal, dentre outras entidades clínicas ${ }^{(3)}$. Nesse sentido, Quando a dor permanece durante toda a mamada contribui sobremaneira para a mãe desmamar seu filho.

As situações relatadas como a síndrome do pouco leite trata-se de uma construção social da medicina higienista para explicar as falhas de seu paradigma de amamentação, Que têm trabalhado para reforçar a Questão cultural desta concepção nos diferentes seguimentos da sociedade. Ao mesmo tempo, a fisiologia da lactação humana tem sido negligenciada ${ }^{(1)}$.

\section{CONSIDERAÇÕES FINAIS}

Os resultados e discussão dos dados deste estudo possibilitaram visualizar o cenário em Que se insere a problemática do desmame precoce, bem como atender aos objetivos a Que se propôs a pesQuisa. Com base nos relatos, constatou-se Que embora a totalidade de mães pesQuisadas reconheçam a importância do leite materno, seis mães amamentaram exclusivamente seus filhos no máximo por três meses e ao contrário do esperado, o acompanhamento do bebê e/ou da mãe pela Equipe de Saúde da Família, não influenciou no tempo de amamentação.

Contudo, ainda que muitos dos fatores apresentados pelas depoentes deste estudo pareçam explicar as causas do desmame precoce, como: problemas relacionados à "falta de leite", "leite fraco", problemas mamários e a recusa do bebê em pegar o peito, além da presença de certas doenças na mulher, o crescimento da participação feminina no mercado de trabalho, dentre outros. É possível sugerir outras razões que o explieuem, ligadas ao ambiente, à personalidade materna, às suas emoções, à relação com o marido e a família, às influências culturais e à sua resposta aos diferentes problemas do cotidiano.

Razões como doenças maternas, trabalho fora de casa, falta de leite e recusa do bebê em pegar o peito, talvez se deva ao fato da mulher atual ter um cotidiano mais ansioso e tenso, e possivelmente, também em virtude da ausência de um suporte cultural Que havia em tempos passados, nas Quais as avós transmitiam às mães informações e um treinamento para as mesmas, em relação ao aleitamento materno.

Portanto, é de fundamental importância Que a mulher sinta-se adequadamente assistida nas suas dúvidas e dificuldades, para Que as mesmas possam assumir com mais segurança o papel de mãe e provedora do aleitamento de seu filho. Cabendo aos profissionais de Saúde, em especial, as enfermeiras e ao Serviço de Saúde o compromisso de realizar um atendimento de Qualidade a essas mães de modo a tornar a amamentação um ato de prazer e não uma obrigação.

\section{REFERÊNCIAS}

I. Almeida |AG. Amamentação: um híbrido natureza-cultura. Rio de Janeiro (RI): Fiocruz; 1999.

2. Machado ARM, Nakano AMS, Almeida AM, Mamede MV. O lugar da mãe na prática da amamentação de sua filha nutriz: o estar junto. Rev Bras Enferm 2004; 57(2): 183-7.

3. Camano L, Sousa E, Sass N, Mattar R. Obstetrícia: guia de medicina ambulatorial e hospitalar. Barueri (SP): Manole; 2005.
4. Faleiros FTV, Trezza EMC, Carandina L. Aleitamento materno: fatores de influência na sua decisão e duração. Rev Nutr 2006; 19(5):623-30.

5. Carrascoza KC, Costa Júnior AL, Moraes ABA. Fatores que influenciam o desmame precoce e a extensão do aleitamento materno. Estudos de Psicologia 200; 22(4): 433-40.

6. Escobar AMU, Ogawa AR, Hiratsuka M, Kawashita MY, et al. 
Araújo $O D$, et al.

Aleitamento materno e condições sócio-econômico-culturais: fatores que levam ao desmame precoce. Rev Bras Saúde Materno-Infantil 2002; 2 (3): 253-61.

7. Palma D. Alimentação da criança nos primeiros anos de vida. Rev Paul Pediatria 1998; I (6): 2 I-6.

8. Caldeira AP, Goulart EMA. A situação do aleitamento materno em Montes Claros, Minas Gerais: estudo de uma amostra representativa. I Pediatria 2000; 76( I): 65-72.
9. Bardin L. Análise de Conteúdo. Lisboa (POR): Edições 70; 1977.

10. Santos NCM. Assistência de enfermagem materno-infantil. São Paulo (SP): latria; 2004

11. Osório CM, Queiroz ABZ. Representações sociais de mulheres sobre a amamentação: teste de associação livre de idéias acerca da interrupção precoce do aleitamento materno exclusivo. Esc Anna Nery Rev Enferm 2007; I I (2). 